\title{
Putative pleiotropic effects of the knockdown resistance (L1014F) allele on the life-history traits of Anopheles gambiae
}

\author{
Adandé A. Medjigbodo 1,2,3, Luc S. Djogbénou ${ }^{1,3,4^{*}}$ (], Oswald Y. Djihinto ${ }^{1,3}$, Romaric B. Akoton1, \\ Emmanuella Abbey ${ }^{1,3}$, Rosaria M. Kakossou ${ }^{1,3}$, Eric G. Sonounameto ${ }^{1,3}$, Esther B. J. Salavi ${ }^{1,3}$, \\ Laurette Djossou ${ }^{3}$ and Athanase Badolo ${ }^{2}$
}

\begin{abstract}
Background: Existing mechanisms of insecticide resistance are known to help the survival of mosquitoes following contact with chemical compounds, even though they could negatively affect the life-history traits of resistant malaria vectors. In West Africa, the knockdown resistance mechanism $k d r^{R}(\mathrm{~L} 1014 \mathrm{~F})$ is the most common. However, little knowledge is available on its effects on mosquito life-history traits. The fitness effects associated with this knockdown resistance allele in Anopheles gambiae sensu stricto (s.s.) were investigated in an insecticide-free laboratory environment.
\end{abstract}

Methods: The life-history traits of Kisumu (susceptible) and KisKdr ( $k d r$ resistant) strains of An. gambiae s.s. were compared. Larval survivorship and pupation rate were assessed as well as fecundity and fertility of adult females. Female mosquitoes of both strains were directly blood fed through artificial membrane assays and then the blood-feeding success, blood volume and adult survivorship post-blood meal were assessed.

Results: The An. gambiae mosquitoes carrying the $k d r^{R}$ allele (KisKdr) laid a reduced number of eggs. The mean number of larvae in the susceptible strain Kisumu was three-fold overall higher than that seen in the KisKdr strain with a significant difference in hatching rates (81.89\% in Kisumu vs $72.89 \%$ in KisKdr). The KisKdr larvae had a significant higher survivorship than that of Kisumu. The blood-feeding success was significantly higher in the resistant mosquitoes (84\%) compared to the susceptible ones (34.75\%). However, the mean blood volume was $1.36 \mu \mathrm{L} / \mathrm{mg}, 1.45 \mu \mathrm{L} /$ $\mathrm{mg}$ and $1.68 \mu \mathrm{L} / \mathrm{mg}$ in Kisumu, homozygote and heterozygote KisKdr mosquitoes, respectively. After blood-feeding, the heterozygote KisKdr mosquitoes displayed highest survivorship when compared to that of Kisumu.

Conclusions: The presence of the knockdown resistance allele appears to impact the life-history traits, such as fecundity, fertility, larval survivorship, and blood-feeding behaviour in An. gambiae. These data could help to guide the implementation of more reliable strategies for the control of malaria vectors.

Keywords: Kdr allele, Fitness effects, Life-history traits, Anopheles gambiae, Malaria

*Correspondence: Idjogbenou22002@yahoo.fr

${ }^{1}$ Tropical Infectious Diseases Research Centre (TIDRC), University of Abomey-Calavi, 01BP 526 Cotonou, Benin

Full list of author information is available at the end of the article

\section{Background}

Malaria is still one of the most devastating parasitic diseases, especially in tropical regions worldwide. This disease spreads in 96 countries in America, many parts of Asia and most of Africa [1]. Malaria is transmitted through the bite of infected female Anopheles 
mosquitoes, which carry the infection by protozoan parasites Plasmodium species to humans [2]. In most regions in sub-Saharan Africa, mosquito species including Anopheles gambiae sensu stricto (s.s.), Anopheles arabiensis, Anopheles coluzzii, and Anopheles funestus are the main vectors that transmit malaria parasites [3-5]. Since an effective malaria vaccine is yet to become available, vector control remains the main strategy for the prevention of malaria transmission [6]. Indeed, longlasting insecticide-treated nets (LLINs) and indoor residual spraying (IRS) remain the backbone of malaria vector control and have been shown to contribute to malaria control through the reduction of human-vector contact [7]. Unfortunately, insecticide resistance to pyrethroids (permethrin, deltamethrin) and other classes of insecticides has been reported in An. gambiae, the main malaria vector in several African countries [8-14]. The major insecticide resistance mechanisms in An. gambiae consist of target sites insensitivity $\left(a c e-1^{\mathrm{R}}\right.$ and $\left.k d r^{\mathrm{R}}\right)$ and increased metabolic activity of detoxifying enzymes [15-20]. In An. gambiae s.s., mutations related to pyrethroids and dichlorodiphenyltrichloroethane (DDT) resistance are located mainly at codon 1014 within the transmembrane segment 6 of domain II in the Voltagegated sodium channel (Vgsc) gene. These mutations lead to a change of leucine to either phenylalanine (L1014F) or serine (L1014S) [21, 22]. Further, additional mutation at position 1575 of the linker between domains III-IV in the Vgsc resulting in asparagine-to-tyrosine substitution (N1575Y) has been found occurring solely on a L1014Fbearing haplotype [23]. Recent studies carried out in Benin [24], Ivory Coast [25] and Burkina Faso [26] have shown that the L1014F allele frequency is almost fixed in wild An. gambiae mosquitoes. However, little is known about the fitness cost induced by this homozygous resistance allele in the malaria vector An. gambiae.

Although resistance alleles confer the potential of surviving particular insecticide exposures to mosquitoes, it is often assumed that they may also influence various fitness-related traits of mosquitoes (e.g., trophic behaviour, fecundity, fertility, parasite transmission, longevity, and larval survivorship) in the presence or absence of insecticide selection pressure [27]. Therefore, better understanding the effects of resistance alleles on the most important life-history traits of mosquitoes appears crucial to improve malaria vector control interventions.

Several studies have shown that insecticide resistance mechanisms can confer detrimental effects on reproductive fitness, host-seeking, feeding and mating behaviours in Anopheles mosquitoes [28-30] as well as in some Aedes [31-33] and Culex mosquitoes [34-36]. Decreased longevity and increased larval survivorship have also been observed in insecticide-resistant strains of Aedes aegypti, Culex pipiens and An. gambiae [31, 37-40]. A study carried out by Platt et al. [30] revealed that $k d r^{\mathrm{R}}$ heterozygous males An. coluzzii were more likely to successfully mate than homozygote-resistant ones, illustrating a deleterious effect of homozygote-resistant $k d r^{\mathrm{R}}$ allele on An. coluzzii paternity success. Also, they were more competitive compared to homozygous-susceptible mosquitoes indicating a heterozygous fitness advantage [30]. Furthermore, it was demonstrated that pupae of An. gambiae homozygous for ace-1 ${ }^{\mathrm{R}}$ (G119S) allele were more likely to die during the pupation stage than those of the susceptible strain [40]. All these studies highlight the variability of mosquito life-history traits according to species and the effects of specific insecticide resistance mechanisms on these traits.

Herein, the relative effects of $k d r^{\mathrm{R}}$ (L1014F) allele on reproductive success, larval survivorship, blood-feeding behaviour, and adult survivorship post-blood meal in $A n$. gambiae s.s. were evaluated.

\section{Methods \\ Mosquito strains and rearing}

Two laboratory reference strains of An. gambiae s.s. were used. The insecticide-susceptible reference strain Kisumu, sampled from Kenya the early 1950s and was maintained at insectary [41]. The KisKdr strain, which is homozygous $\left[k d r^{R R}\right]$ for the L1014F allele and resistant to both pyrethroids and organochlorines, was obtained by introgression of the $k d r^{\mathrm{R}}$ (L1014F) allele into the Kisumu genome [42]. This strain has the same genetic background as Kisumu $\left[k d r^{\mathrm{SS}}\right]$ and was free of metabolic resistance.

In order to investigate the role of $k d r^{\mathrm{R}}$ (L1014F) allele in An. gambiae s.s. blood-feeding behaviour, heterozygote $\left[k d r^{\mathrm{RS}}\right]$-resistant mosquitoes were obtained by crossing Kisumu females $\left[k d r^{S \mathrm{~S}}\right]$ with KisKdr males $\left[k d r^{\mathrm{RR}}\right]$ and Kisumu males with KisKdr females encoded F1-1 (\$Kisumu X ${ }^{\star} \mathrm{K}$ KisKdr) and F1-2 ( ${ }^{\star}$ Kisumu X $\$$ KisKdr), respectively. For routine rearing in the insectary at the Regional Institute of Public Health/ University of AbomeyCalavi (Benin), these strains were reared under soft conditions (insecticide-free laboratory environment) in a climate-controlled room at a temperature fixed at $27{ }^{\circ} \mathrm{C}$ $( \pm 0.2)$, a relative humidity of $70 \%( \pm 8)$ and $12: 12$ light and dark period. Larvae were reared in plastic trays (about $30 \times 20 \mathrm{~cm}$ ) and fed with TetraMin Baby fish food. Pupae were collected and placed in small plastic cups inside a fresh cage for adult emergence. Adult mosquitoes were kept in $30 \times 30 \times 30 \mathrm{~cm}$ insect cages (produced locally) and continuously supplied. Mosquitoes were fed ad libitum on $10 \%$ honey solution (made with deionized water) until they were ready to be used for further assays. Female individuals were blood-fed on laboratory rabbits (used for 
the purpose of blood-feeding mosquitoes) twice a week. Gravid females were allowed to oviposit in plastic petri dishes containing a water-soaked cotton covered with filter paper. The eggs were collected and put in plastic trays containing dechlorinated water $(1 \mathrm{~L}$ per tray) for hatching.

\section{Female reproductive success assessment}

Three days after emergence from the larval-rearing conditions described, 180 An. gambiae females of both KisKdr ( $\mathrm{n}=90)$ and Kisumu $(\mathrm{n}=90)$ strains were bloodfed on a laboratory rabbit. The gravid mosquitoes of each strain were individually transferred into plastic cups containing wet Whatman filter paper for oviposition. They were allowed to feed on $10 \%$ honey solution until egg laying. The number of females that laid eggs was recorded and the eggs were counted under a stereomicroscope (Leica Microsystems EZ4HD). Egg batches (from individual females) were transferred in separate plastic trays (about $10 \mathrm{~cm}$ diameter) filled with dechlorinated water and the number of hatched larvae was recorded. The experiments were performed two times.

\section{Larval survival assessment}

The larvae from each mosquito strain reared in insecticide-free laboratory conditions as described, were used for the survival assays. To assess larval mortality associated with $k d r^{\mathrm{R}}$ (L1014F) allele in each mosquito strain, assays were performed as described by Yahouédo et al. [43]. In total, 480 first instar larvae (L1) of each mosquito strain were used. For each replicate, 32 larvae were pipetted into a $50 \mathrm{~mL}$ graduated plastic beaker $(9 \mathrm{~cm}$ diameter). The beaker was filled with dechlorinated water to the $32 \mathrm{~mL}$ mark and larvae were then poured into a new petri dish. The petri dishes remained covered with the lids and their positions were changed every day to compensate for any localized differences that may exist on the rack. Petri dishes were used in order to reduce variation in larval growth rate. Every day, the larvae of each petri dish were fed with $640 \mu \mathrm{g}$ of TetraMin Baby fish food. Water was changed every two days to reduce the effect of pollution. The petri dishes containing larvae were inspected once daily and the dead pupae or larvae were recorded and removed. Daily mortality of larvae was monitored until the last one reached pupal stage. The experiments were performed three times.

\section{Assessment of blood-feeding behaviour}

Membrane feeding assays (MFAs) previously described by Kristan et al. [44] were performed to blood-feed the mosquitoes. The 3-5-days old females of Kisumu $(n=495)$, KisKdr $(n=200)$ and those from the crossings, namely F1-1 $(n=95)$ and F1-2 $(n=105)$, were used in three different experiments. Mosquitoes were glucose-starved (with access to water-soaked cotton) for $24 \mathrm{~h}$ and the batches of 25 individuals were separately exposed for $30 \mathrm{~min}$ to membrane feeders containing the blood sample pre-heated following procedures described in [45]. The fully blood-fed mosquitoes were scored $24 \mathrm{~h}$ later and were kept for survivorship assessment post-blood feeding.

A portion of the blood-fed mosquitoes was used to assess the blood meal size using a spectrophotometer (MULTISCAN GO, Thermo Scientific) as previously described [46]. Each experiment using at least 30 individuals per strain, was performed three times.

\section{Mosquito longevity post-blood meal}

After the blood-feeding assays, successfully blood-fed females from Kisumu $(n=172)$, KisKdr $(n=168)$, F1-1 $(\mathrm{n}=71)$ and F1-2 $(\mathrm{n}=90)$ were transferred into brandnew disposable paper cups (an average 10 females per cup) and were allowed to feed on $10 \%$ honey solution. The mortality was recorded daily until the death of the last mosquito.

\section{Data analysis}

Data were recorded in appropriate designed forms, entered into Microsoft Excel for data cleaning and exported to R statistical software version 3.4.4 [47] and GraphPad Prism 8.0.2 software (San Diego, CA, USA) for analysis. The normality of data distribution was checked using Shapiro Wilk test [48].

Fecundity of each mosquito strain was assessed as the total number of eggs over the total number of females that contributed to oviposition. A correlation between $k d r^{\mathrm{R}}$ genotype and fecundity was calculated using negative binomial model (NBM) defined as follow: $\log$ $(\mathrm{Ov})=$ Genotype $+\varepsilon$ where $\mathrm{Ov}$ is the number of eggs/ female; Genotype is the two-level factor corresponding to the different genotypes tested; $\varepsilon$ is the error parameter which follows a negative binomial distribution. For each mosquito strain, fertility was evaluated as percentage of hatched larvae by dividing the total number of first instar larvae over the total number of eggs. A correlation between $k d r^{\mathrm{R}}$ genotype and fertility was calculated using NBM, defined as follow: log $(\mathrm{Ha})=$ Genotype $+\varepsilon$ where $\mathrm{Ha}$ is the percentage of larvae/egg batch. Descriptive statistics were used to calculate pupation percentage (number of pupae/number of first instar larvae), blood-fed mosquito percentage (number of blood-fed mosquitoes/number of exposed mosquitoes). The Chi-square independence test was performed to compare proportions using the R statistical software [47]. The Mann-Whitney procedure was used to compare the means between mosquito strains. For the larval and blood-fed females survivorships, differences in the computed survival curves of Kisumu 
and KisKdr strains were analysed using Kaplan-Meier pair-wise comparisons [49]. The Log-rank test was performed to evaluate the difference in survival time between the mosquito strains [50]. Differences in larval survival time and in adult survival time post-blood meal between the two genotypes were tested using Cox proportional hazards regression model (Cox model) with a binomial error distribution. The models were calculated as follows: Survival=Genotype $+\varepsilon$, where Survival is a proportion of dead larvae or adults; Genotype is the two-level factor corresponding to the different genotypes tested; $\varepsilon$ is the error parameter which follows a binomial distribution. The pupae were censored in the larval survivorship analysis. The significance of differences in blood-feeding rates between the genotypes was assessed with the following generalized linear models $(\mathrm{GLM})$ : Fed $=$ Genotype $+\varepsilon$, where Fed is the blood-fed status; Genotype is a three-level factor corresponding to the different genotypes tested $\left(\left[k d r^{\mathrm{SS}}\right],\left[k d r^{\mathrm{RS}}\right]\right.$ and $\left.\left[k d r^{\mathrm{RR}}\right]\right) ; \varepsilon$ is the error parameter which follows a binomial distribution. All these analyses were set at significance threshold of $p<0.05$.

\section{Results}

\section{Reproductive success}

The mean number of eggs laid per mosquito female (fecundity) and the average larval hatching rate (fertility) were significantly different between the two strains $(30.72 \pm 19.92 \mathrm{eggs} / \mathrm{KisKdr}$ female vs $87.98 \pm 44.51$ eggs/Kisumu female, $p=1.07 \times 10^{-10}$; Fig. 1) and $(72.89 \pm 15.7 \%$ hatched larvae/KisKdr female vs $81.89 \pm 12.4 \%$ for Kisumu female, $p=0.02 \times 10^{-1}$; Fig. 2). Moreover, the KisKdr female fecundity and fertility decreased by 1.05 (GLM.NB: $F=58.21, \Delta d f=1$, $p=8.71 \times 10^{-12}$ ) and 0.12 (GLM.NB: $\chi^{2}=1062, \Delta d f=1$, $\left.p=0.01 \times 10^{-1}\right)$, respectively, when compared to those of Kisumu females. Overall, the reproductive success of KisKdr $\left[k d r^{R R}\right]$ females was significantly lower than that of Kisumu $\left[k d r^{\mathrm{SS}}\right]$ females.

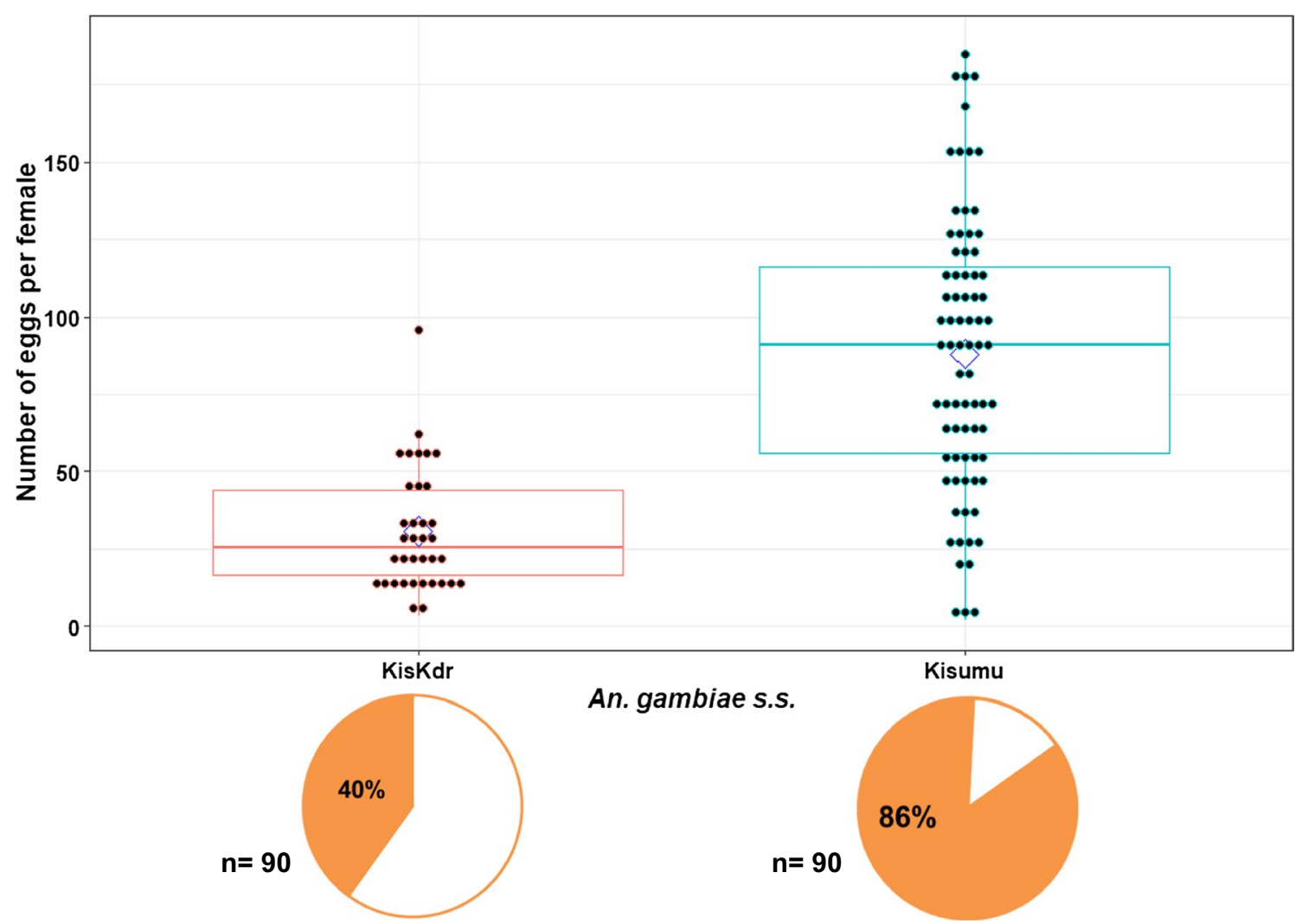

Fig. 1 Fecundity in KisKdr and Kisumu strains. Each dot denotes the number of eggs laid by each female in each strain. Only females that laid at least one egg were included. A diamond point represents the mean number of eggs in each strain and the box plots represent the median and its 25 and 75\% interquartile. Pie charts represent percentages of mosquito females that laid eggs in each strain. (n) indicates the total number of mosquito females subjected to the oviposition. Significant difference was observed in fecundity between both Kisumu and Kiskdr mosquito females $\left(p=1.07 \times 10^{-10}\right)$ 


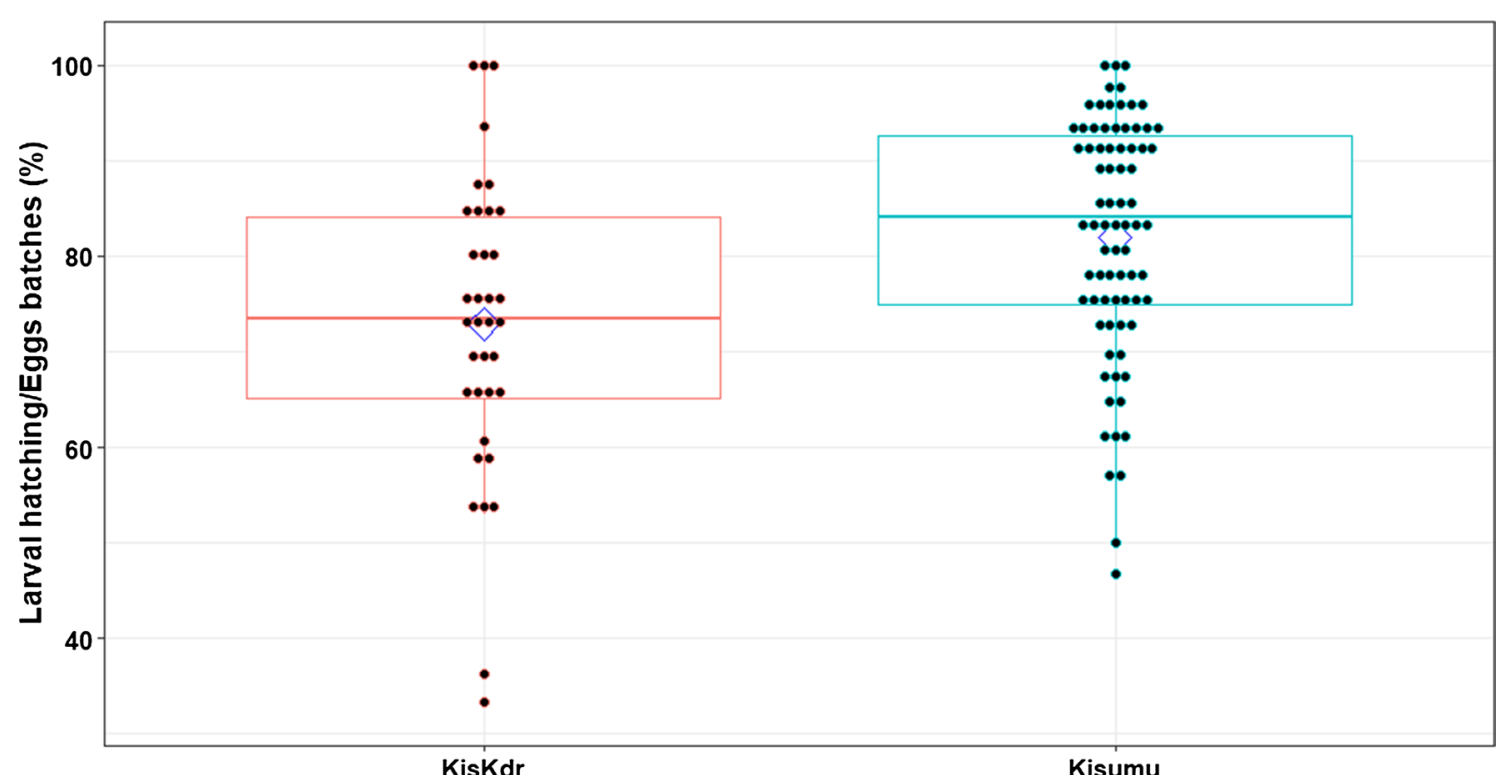

An. gambiae s.s.

Fig. 2 Kisumu and KisKdr larval-hatching percentages. Each dot denotes the percentage of larvae hatched from individual female eggs batch within each strain. A diamond point represents the mean percentage of larvae hatched from each strain and the box plot represents the median and $25 \%$ and $75 \%$ interquartile ranges. Significant difference was observed in hatching rates between both Kisumu and KisKdr females $\left(p=0.02 \times 10^{-1}\right)$

\section{Larval survivorship}

The median survival times of Kisumu and KisKdr larvae were, respectively, 10 days and 11 days (Fig. 3A).
However, the survival time of Kisumu larvae was significantly shorter than that of KisKdr larvae (Log-rank test: $\left.\chi^{2}=110, \Delta d f=1, p=2 \cdot 10^{-16}\right)$. Furthermore, more than
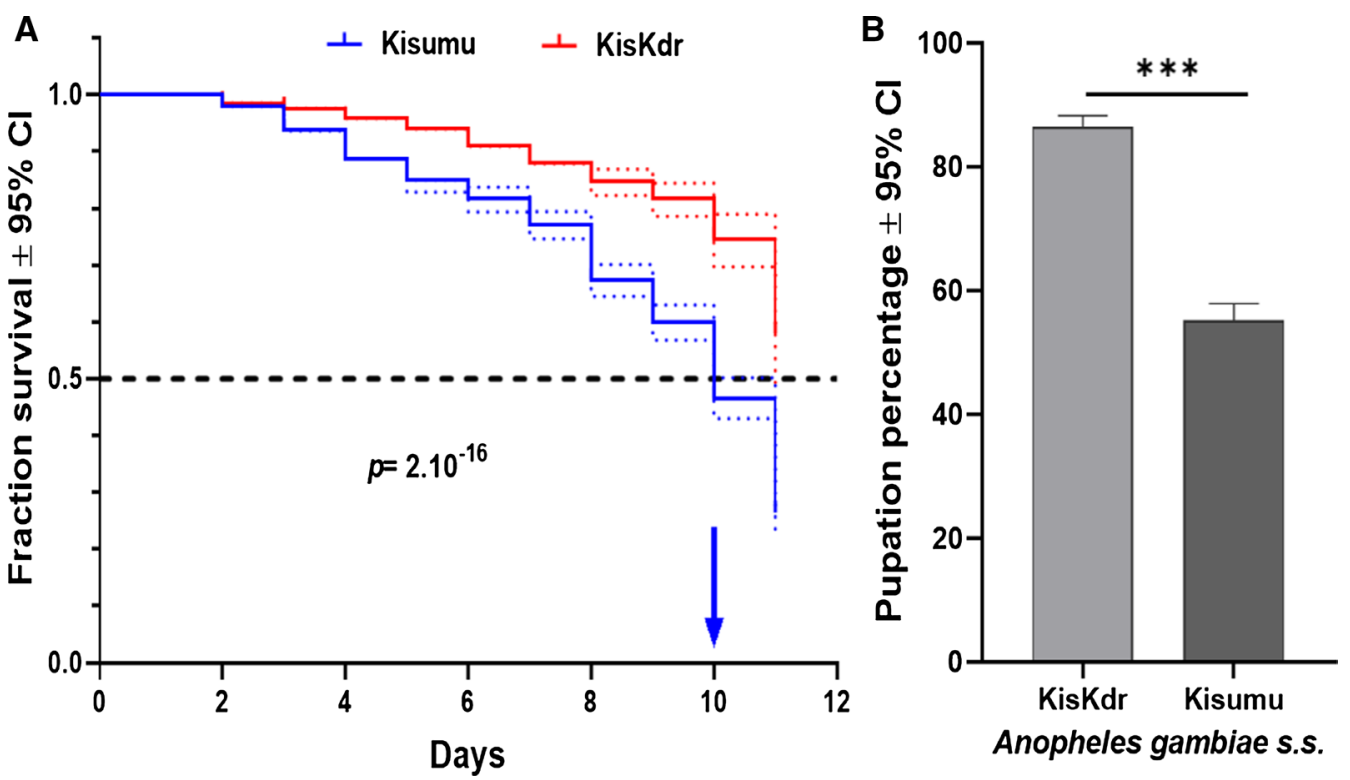

Fig. 3 KisKdr and Kisumu larvae longevity A and pupation percentages B. A Dotted lines are 95\% confidence intervals (Cls) around the respective survival curve. Arrow indicates the median survival time. B Error bars are $95 \%$ confidence intervals (Cls) around each percentage. ${ }^{* *}$ indicate $p=0.01 \times 10^{-2}$ 
$50 \%$ of KisKdr larvae were still alive and have reached the pupal stage at the end of the larval following-up period (Fig. 3A). The risk of death of individual larvae when bearing $k d r^{R}$ allele at homozygote state $\left[k d r^{R R}\right]$ is reduced by a factor of $59 \%$ compared to homozygote susceptible larvae $\left[k d r^{\mathrm{SS}}\right]$ (Cox model: likelihood ratio test (LRT): $\left.\chi^{2}=114.7, \Delta d f=1, p=2.10^{-16}\right)$. Consequently, pupation rate in KisKdr females was significantly higher (85.84\%, $\left.\mathrm{CI}_{95 \%}=[84.12-87.75]\right)$ than that recorded for Kisumu strain $\left(54.05 \%, \mathrm{CI}_{95 \%}=[51.34-56.74]\right)$ (Fig. 3B).

\section{Blood-feeding success}

Overall, 84\% (168/200) of KisKdr females and 34.75\% (172/495) of Kisumu females subjected to the assays took a blood meal, as shown in Fig. 4A. The KisKdr females showed a significantly higher blood-feeding rate than the Kisumu ones $\left(\chi^{2}=136.32, d f=1, p=2.2 \times 10^{-16}\right)$. Interestingly, the offspring heterozygote $\left[k d r^{\mathrm{RS}}\right]$ females F1-1 and F1-2 displayed also consistently higher per cent of blood-fed individuals (respectively, 74.74\% (71/95) and $85.71 \%(90 / 105))$ than that of Kisumu $\left[k d r^{\mathrm{SS}}\right]$ individuals $\left(x^{2}=121.89, d f=2, p=2.2 \times 10^{-16}\right)$ (Fig. 4A). In all cases, mosquitoes harbouring the $k d r^{\mathrm{R}}$ allele at both homozygote and heterozygote states showed higher bloodfeeding ability compared to the susceptible homozygote Kisumu strain (GLM: (RLT): $\chi^{2}=215.28, \Delta d f=2$, $\left.p=2.2 \times 10^{-16}\right)$.

When using other batches of mosquito females for the same blood-feeding assays, the average blood volume ingested by KisKdr individuals, was similar to that of Kisumu specimens $(p=0.22)$ while the average amount of blood ingested by the heterozygous offspring $(1.68 \mu \mathrm{L} /$ $\mathrm{mg})$ was significantly higher than for Kisumu mosquitoes $(1.36 \mu \mathrm{L} / \mathrm{mg})\left(p=8.10^{-4}\right)$, as shown in Fig. $4 \mathrm{~B}$.

\section{Adult female survivorships post-blood feeding}

The median survival times after blood-feeding of the homozygous susceptible (Kisumu) and resistant (KisKdr) mosquitoes were, respectively, 7 days and 8 days (Fig. 5A). No significant difference in the survival time was observed between the two strains (Log-rank test: $\left.\chi^{2}=0.6, \Delta d f=1, p=0.4\right)$.

Moreover, the offspring heterozygote $\left[k d r^{\mathrm{RS}}\right]$ displayed a longer median survival time after blood-feeding (10 days) compared to those of their parents ( 8 days for KisKdr; Log-rank test: $\chi 2=48, \Delta d f=2, p=4.10^{-11}$ and 7 days for Kisumu; Log-rank test: $\chi^{2}=54.9, \Delta d f=2$, $p=10^{-12}$ ). In addition, these offspring displayed a higher survival rate when compared to KisKdr females (hazard ratio $=0.44$; Cox model: (LRT): $\chi 2=38.12, \Delta d f=1$, $p=7.10^{-10}$ ) and Kisumu specimens (hazard ratio $=0.41$; Cox model: (LRT): $\chi^{2}=44.93, \Delta d f=1, p=2.10^{-11}$ ) as shown in Fig. 5A, B.

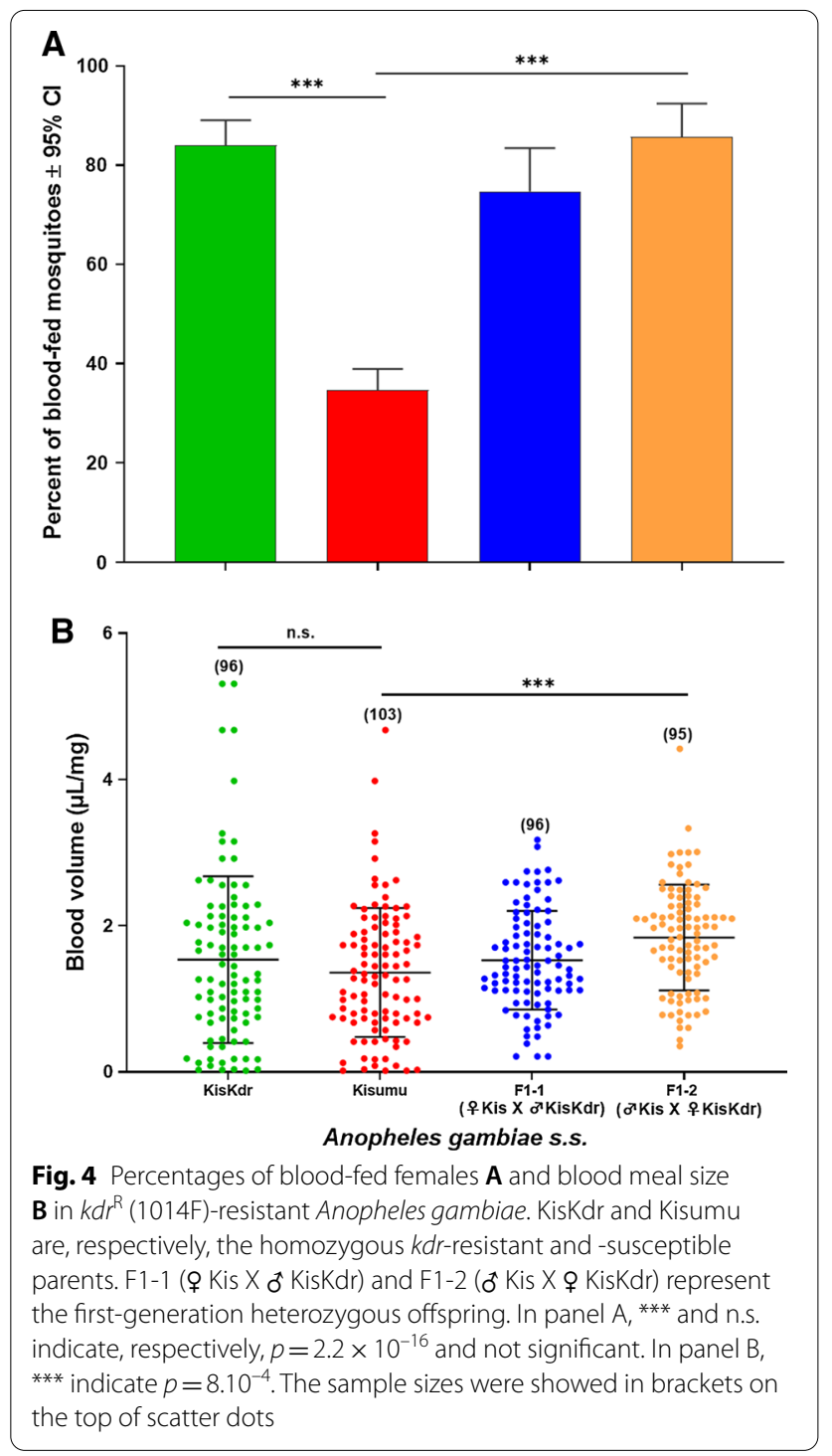

\section{Discussion}

In the dominant malaria vector $A n$. gambiae, pyrethroid resistance is spreading over time and space on the African continent, supported by several point mutations in the Voltage-gated sodium channel gene $[21,23,51]$. It was demonstrated that alleles conferring resistance in mosquito populations allow the mosquito to survive longer in an area of insecticide pressure but may alter some vector life-history traits [30, 31, 52] in an insecticide-free environment. Understanding and documenting the effects of $k d r$ allele on life-history traits of $A n$. gambiae, is a key for developing evidencebased resistance management strategies, including suppression of the insecticide selection pressure that allows the susceptible alleles to become more predominant [53]. 

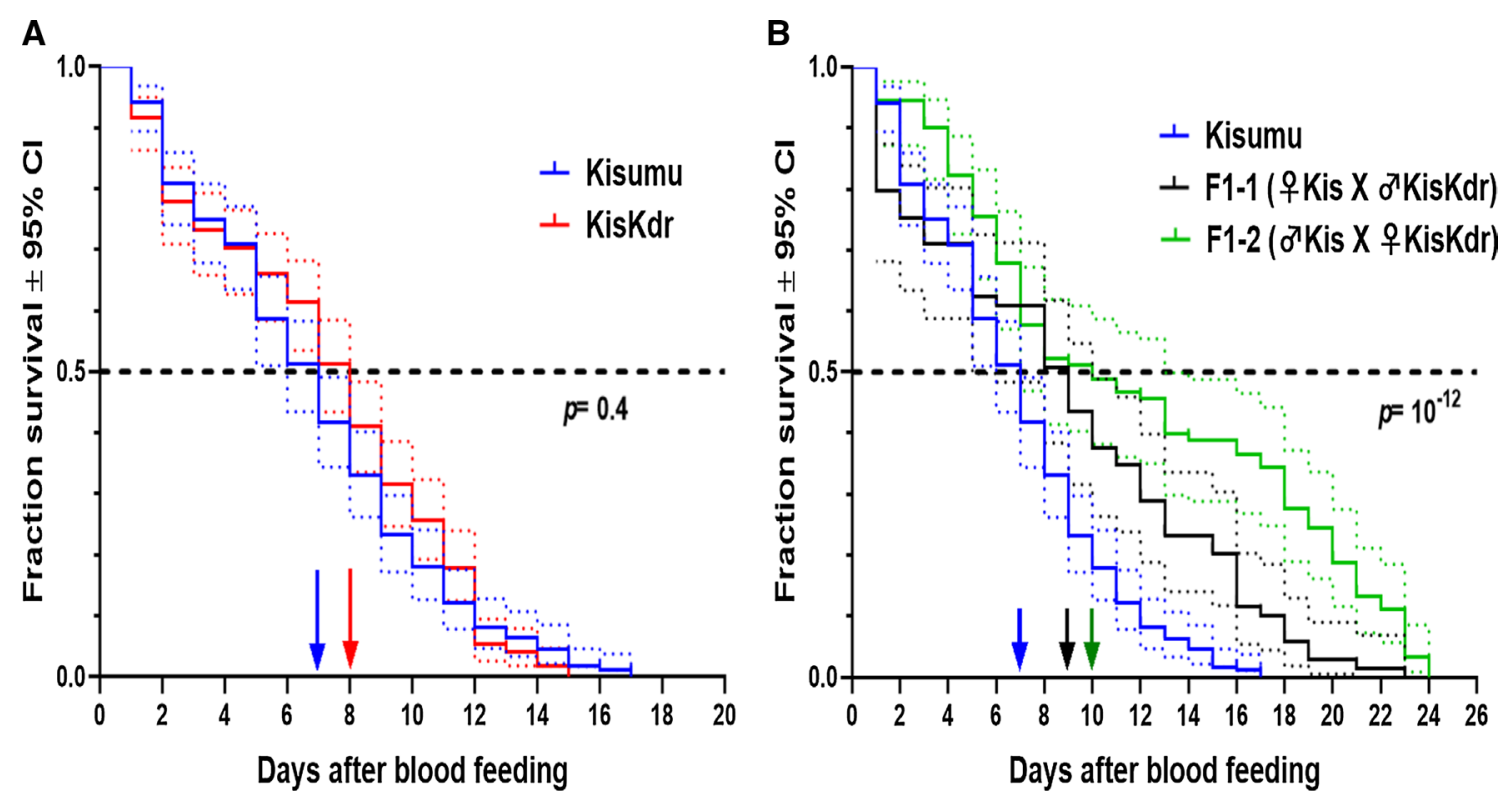

Fig. 5 Parents and first generation female longevity after blood-feeding. Dotted lines are 95\% confidence intervals (Cls) around the respective survival curve. Arrows indicate the median survival time

This study has investigated the pleiotropic effects associated with the presence of the West African knockdown resistance allele (L1014F) on the reproductive success, larval and adult survivorships and blood-feeding success in laboratory $A n$. gambiae s.s. by comparing the susceptible and resistant strains (homozygous $k d r$ genotype) which share the same genetic background but differ in the presence or absence of the $k d r^{R}$ (L1014F) allele. Reduced egg production and egg hatchability have been reported in other insecticide-resistant mosquito species, including Ae. aegypti $[31,54,55]$. However, in An. funestus, the egg production rates between pyrethroid-resistant and susceptible strains did not vary significantly [56]. The current study reported significantly lower fecundity and fertility in the homozygous KisKdr individuals compared to susceptible Kisumu strain mosquitoes. These results suggest that the $k d r^{\mathrm{R}}$ allele negatively affected the ability for egg production and hatchability in resistant homozygote $\left[k d r^{\mathrm{RR}}\right]$ An. gambiae. Consequently, reduced larval production would reduce adult density and lead to a decreased level of malaria parasite transmission in the resistant $A n$. gambiae mosquitoes.

This study revealed that the $k d r^{\mathrm{R}}$ (L1014F) allele confers a high larval-to-pupal survivorship and pupation rate in KisKdr mosquitoes compared to the susceptible strain. This suggests that both life-history traits are positively affected by the presence of the $k d r$ allele. Relatively long larval development time and reduced survival time have previously been observed in insecticide-resistant $A n$. gambiae [57]. It was recently demonstrated that insecticides in the larval environment (containing a lower dose of pyrethroid insecticide with a variation of food availability) could significantly influence the immune response of adults An. gambiae [58]. Indeed, the exposure of pyrethroid-resistant larvae (having escaped potential predators) to sub-lethal doses of insecticide residues during their aquatic developmental stage, especially in agricultural areas, could further affect the adult life-history traits. Such a phenomenon could drive the emergence of new outcomes related to the infection with specific mosquito-borne pathogens and the persistence of insecticide-resistant An. gambiae, which is still an essential impediment to the malaria vector control measures.

The results from this work indicate a significant association between harbouring of $k d r^{\mathrm{R}}$ allele and the high blood-feeding success in An. gambiae s.s.. This result suggests that the L1014F $k d r$ allele may increase the ability of An. gambiae to blood-feed. By contrast, an absence of association was observed for the blood meal volume. Previous work on insecticide resistance markers has shown an association between the CYP6P9a gene (a marker of cytochrome $\mathrm{P} 450$, which mediates metabolic resistance again pyrethroid insecticides) and the feeding success and blood meal size in An. funestus [59]. These findings highlight the need for further studies to improve knowledge of the influence of multiple insecticide resistance markers harbouring on the propensity of malaria vectors to blood feed. However, heterozygous KisKdr F1-1 
and F1-2 mosquitoes ingested higher blood volume compared to Kisumu specimens.

Gametocyte-infected mosquitoes must survive long enough to become infectious and transmit sporozoites to a new host [60]. One of the key factors modulating malaria transmission is the vector longevity after bloodfeeding. This study demonstrates that the presence of $k d r^{\mathrm{R}}$ allele seems to increase the longevity of heterozygote KisKdr mosquitoes while no survival advantage was observed in homozygous individuals compared to the susceptible strain Kisumu. This benefit in heterozygote $\left[k d r^{\mathrm{RS}}\right]$ over homozygote $\left[k d r^{\mathrm{RR}}\right]$ makes the $k d r$ an over-dominant gene for this specific trait. The heterozygote mosquitoes survived until 24 days post-blood meal. Thus, these specimens have sufficient lifespan to allow an extrinsic incubation period of Plasmodium parasites if they ingest gametocyte-infected blood. However, further investigations are needed to evaluate the cost of Plasmodium infection to heterozygote-resistant KisKdr mosquito survivorship.

\section{Conclusion}

In order to generate valuable predictions of malaria transmission, the impact of resistance mechanisms on the vector life-history traits needs to be taken into consideration. The data presented here indicate that $k d r^{\mathrm{R}}$ allele induces a cost on fecundity and fertility in adult An. gambiae. Remarkably, this allele positively affects the larval survivorship, pupation rate, blood-feeding success in homozygote-resistant mosquitoes, and increases the post-blood feeding survivorship, especially in heterozygote individuals. It would be interesting to characterize the fitness effects of $k d r^{\mathrm{R}}$ allele in natural populations of An. gambiae and identify the potential synergist genes.

\begin{abstract}
Abbreviations
$K d r^{R}$ : Resistant allele of knockdown resistance; $K d r^{S}$ : Susceptible allele of knockdown resistance; ace- $1^{R}$ : Resistant allele of insecticide-insensitive acetylcholinesterase-1; S.S.: Sensu stricto; L1014F: Leucine substitution by phenylalanine at codon 1014; L1014S: Leucine substitution by serine at codon 1014; N1575Y: Asparagine-to-tyrosine substitution at codon 1575; LLINs: Long-lasting insecticide-treated nets; IRS: Indoor residual spraying; G119S: Glycine substitution by serine at codon 119; Vgsc: Voltage-gated sodium channel; GLM: Generalized linear models; NBM: Negative binomial model; MFAs: Membrane feeding assays; LRT: Likelihood ratio test.
\end{abstract}

\section{Acknowledgements}

This study and AAM received financial support by grant to LSD from Wellcome Trust (intermediate fellowship in public health and tropical medicine ${ }^{\circ}$ 109917/Z/15/Z). The authors thank Professor Norbert Hounkonnou, Director of Académie Nationale des Sciences, Arts et Lettres du Bénin (ANSALB) for providing material support. We are also grateful to Janet Midega at the KEMRI-Wellcome Trust Research Programme for the proofreading of the final manuscript.

\section{Authors' contributions}

Conception and design of the work: LSD and AAM. Acquisition of data: AAM, EA, RMK, EGS, EBJS, LD, OYD and RBA. Analysis and interpretation of data: AAM,
OYD and RBA. Drafting and substantial revision of the manuscript: LSD, AAM, OYD, RBA and AB. All authors read and approved the final manuscript.

Funding

Not applicable.

\section{Availability of data and materials}

The datasets are available from the corresponding author on reasonable request.

\section{Declarations}

\section{Ethics approval and consent to participate}

The rabbits used in this study were bought and maintained in standard animal breeding conditions. Injections to animals and veterinary procedures were strictly conducted by a registered Beninese veterinary staff. Blood-feeding protocol and ethics complied with the International Council for Laboratory Animal Science (ICLAS) ethical guidelines. This study did not involve human participants.

\section{Consent for publication}

All authors have read and approved the final version of manuscript and consent to its publication.

\section{Competing interests}

The authors declare that they have no competing interests for this study.

\section{Author details}

${ }^{1}$ Tropical Infectious Diseases Research Centre (TIDRC), University of AbomeyCalavi, 01BP 526 Cotonou, Benin. ${ }^{2}$ Laboratory of Fundamental and Applied Entomology, University Joseph Ki-Zerbo, BP 7021 Ouagadougou 03, Burkina Faso. ${ }^{3}$ Regional Institute of Public Health/University of Abomey-Calavi, BP 384 Ouidah, Benin. ${ }^{4}$ Department of Vector Biology, Liverpool School of Tropical Medicine, Pembroke Place, Liverpool L3 5QA, UK.

Received: 27 October 2020 Accepted: 3 December 2021

Published online: 20 December 2021

\section{References}

1. WHO . Global Malaria Programme. World Malaria Report. . Geneva: World Health Organization; 2017.

2. Bousema T, Drakeley C. Epidemiology and Infectivity of Plasmodium falciparum and Plasmodium vivax gametocytes in relation to malaria control and elimination. Clin Microbiol Rev. 2011;24:377-410.

3. Gillies MT, De Meillon B. The Anophelinae of Africa south of the Sahara. Publ South African Inst Med Res. 1968;54:1-343.

4. Sinka ME, Bangs MJ, Manguin S, Rubio-Palis Y, Chareonviriyaphap T, Coetzee $\mathrm{M}$, et al. A global map of dominant malaria vectors. Parasit Vectors. 2012;5:69.

5. Gillies MT, Coetzee M. A supplement to the Anophelinae of Africa south of the Sahara (Afrotropical Region). Publ South African Inst Med Res. 1987;55:1-143.

6. Katureebe A, Zinszer K, Arinaitwe E, Rek J, Kakande E, Charland K, et al. Measures of malaria burden after long-lasting insecticidal net distribution and indoor residual spraying at three sites in Uganda: a prospective observational study. PLoS Med. 2016;13:e1002167.

7. Karunamoorthi K. Vector control: a cornerstone in the malaria elimination campaign. Clin Microbiol Infect. 2011;17:1608-16.

8. Ranson H, N'Guessan R, Lines J, Moiroux N, Nkuni Z, Corbel V. Pyrethroid resistance in African anopheline mosquitoes: what are the implications for malaria control? Trends Parasitol. 2011;27:91-8.

9. Mitchell SN, Stevenson BJ, Müller P, Wilding CS, Egyir-Yawson A, Field $S G$, et al. Identification and validation of a gene causing cross-resistance between insecticide classes in Anopheles gambiae from Ghana. Proc Natl Acad Sci USA. 2012;109:6147-52.

10. Knox TB, Juma EO, Ochomo EO, Pates Jamet H, Ndungo L, Chege $P$, et al. An online tool for mapping insecticide resistance in major 
Anopheles vectors of human malaria parasites and review of resistance status for the Afrotropical region. Parasit Vectors. 2014;7:76.

11. Agossa FR, Gnanguenon V, Anagonou R, Azondekon R, Aïzoun N, Sovi A, et al. Impact of Insecticide Resistance on the Effectiveness of Pyrethroid-Based Malaria Vectors Control Tools in Benin: Decreased Toxicity and Repellent Effect. PLoS ONE. 2015;10:e0145207.

12. Lynd A, Oruni A, van't Hof AE, Morgan JC, Naego LB, Pipini D, et al. Insecticide resistance in Anopheles gambiae from the northern Democratic Republic of Congo, with extreme knockdown resistance $(k d r)$ mutation frequencies revealed by a new diagnostic assay. Malar J. 2018;17:412.

13. Salako AS, Ahogni I, Aikpon R, Sidick A, Dagnon F, Sovi A, et al. Insecticide resistance status, frequency of L1014F Kdr and G119S Ace-1 mutations, and expression of detoxification enzymes in Anopheles gambiae (s.l.) in two regions of northern Benin in preparation for indoor residual spraying. Parasit Vectors. 2018;11:618.

14. Collins E, Vaselli NM, Sylla M, Beavogui AH, Orsborne J, Lawrence G, et al. The relationship between insecticide resistance, mosquito age and malaria prevalence in Anopheles gambiae s.l. from Guinea. Sci Rep. 2019;9:1-12.

15. Weill M, Lutfalla G, Mogensen K, Chandre F, Berthomieu A, Berticat $C$, et al. Insecticide resistance in mosquito vectors. Nature. 2003:423:136-7.

16. Weill M, Malcolm C, Chandre F, Mogensen K, Berthomieu A, Marquine M, et al. The unique mutation in ace-1 giving high insecticide resistance is easily detectable in mosquito vectors. Insect Mol Biol. 2004;13:1-7.

17. Corbel V, N'Guessan R, Brengues C, Chandre F, Djogbenou L, Martin T, et al. Multiple insecticide resistance mechanisms in Anopheles gambiae and Culex quinquefasciatus from Benin. West Africa Acta Trop. 2007;101:207-16.

18. Dabiré KR, Diabaté A, Djogbenou L, Ouari A, N'Guessan R, Ouédraogo J-B, et al. Dynamics of multiple insecticide resistance in the malaria vector Anopheles gambiae in a rice growing area in South-Western Burkina Faso. Malar J. 2008;7:188.

19. Djogbénou L, Chandre F, Berthomieu A, Dabiré R, Koffi A, Alout $H$, et al. Evidence of introgression of the ace-1R mutation and of the ace-1 duplication in West African Anopheles gambiae s.S. PLoS ONE. 2008;3:e2172.

20. Donnelly MJ, Corbel V, Weetman D, Wilding CS, Williamson MS, BlackWC. Does $k d r$ genotype predict insecticide-resistance phenotype in mosquitoes? Trends Parasitol. 2009;25:213-9.

21. Martinez-Torres D, Chandre F, Williamson MS, Darriet F, Bergé JB, Devonshire AL, et al. Molecular characterization of pyrethroid knockdown resistance (kdr) in the major malaria vector Anopheles gambiae s.s. Insect Mol Biol. 1998;7:179-84.

22. Ranson H, Jensen B, Vulule JM, Wang X, Hemingway J, Collins FH. Identification of a point mutation in the voltage-gated sodium channel gene of Kenyan Anopheles gambiae associated with resistance to DDT and pyrethroids. Insect Mol Biol. 2000;9:491-7.

23. Jones CM, Liyanapathirana M, Agossa FR, Weetman D, Ranson H, Donnelly $\mathrm{MJ}$, et al. Footprints of positive selection associated with a mutation (N1575Y) in the voltage-gated sodium channel of Anopheles gambiae. Proc Natl Acad Sci USA. 2012;109:6614-9.

24. Koukpo CZ, Fassinou AJYH, Ossè RA, Agossa FR, Sovi A, SewadéWT, et al. The current distribution and characterization of the L1014F resistance allele of the kdr gene in three malaria vectors (Anopheles gambiae, Anopheles coluzzii, Anopheles arabiensis) in Benin (West Africa). Malar J. 2019;18:175.

25. Tia E, Chouaibou M, Gbalégba CNG, Boby AMO, Koné M, Kadjo AK. Distribution of species and kdr gene frequency among Anopheles gambiae ss and Anopheles coluzzii populations in five agricultural sites in Côte d'Ivoire (in French). Bull Soc Pathol Exot. 2017;110:130-4.

26. Namountougou M, Soma DD, Kientega M, Balboné M, Kaboré DPA, Drabo SF, et al. Insecticide resistance mechanisms in Anopheles gambiae complex populations from Burkina Faso. West Africa Acta Trop. 2019;197:105054.

27. Rivero A, Vézilier J, Weill M, Read AF, Gandon S. Insecticide control of vector-borne diseases: when is insecticide resistance a problem? PLoS Pathog. 2010;6:e1001000,

28. Siegert PY, Walker E, Miller JR. Differential behavioral responses of Anopheles gambiae (Diptera: Culicidae) modulate mortality caused by pyrethroid-treated bednets. J Econ Entomol. 2009;102:2061-71.
29. Diop MM, Moiroux N, Chandre F, Martin-Herrou H, Milesi P, Boussari O, et al. Behavioral cost \& overdominance in Anopheles gambiae. PLOS ONE. 2015;10:e0121755.

30. Platt N, Kwiatkowska RM, Irving H, Diabaté A, Dabire R, Wondji CS. Targetsite resistance mutations ( $k d r$ and $R D L$ ), but not metabolic resistance, negatively impact male mating competiveness in the malaria vector Anopheles gambiae. Heredity. 2015;115:243-52.

31. Martins AJ, Ribeiro CDeM, Bellinato DF, Peixoto AA, Valle D, Lima JBP. Effect of insecticide resistance on development, longevity and reproduction of field or laboratory selected Aedes aegypti populations. PLoS ONE. 2012;7:e31889.

32. David MR, Garcia GA, Valle D, Maciel-de-Freitas R. Insecticide resistance and fitness: the case of four Aedes aegypti populations from different Brazilian regions. BioMed Res Int. 2018;2018:1-12.

33. Saingamsook J, Yanola J, Lumjuan N, Walton C, Somboon P. Investigation of relative development and reproductivity fitness cost in three insecticide-resistant strains of Aedes aegypti from Thailand. Insects. 2019;10:265.

34. Berticat C, Boquien G, Raymond M, Chevillon C. Insecticide resistance genes induce a mating competition cost in Culex pipiens mosquitoes. Genet Res. 2002;79:41-7.

35. Berticat C, Bonnet J, Duchon S, Agnew P, Weill M, Corbel V. Costs and benefits of multiple resistance to insecticides for Culex quinquefasciatus mosquitoes. BMC Evol Biol. 2008;8:104.

36. Berticat C, Duron O, Heyse D, Raymond M. Insecticide resistance genes confer a predation cost on mosquitoes Culex pipiens. Genet Res. 2004;83:189-96.

37. Li X, Ma L, Sun L, Zhu C. Biotic characteristics in the deltamethrin-susceptible and resistant strains of Culex pipiens pallens (Diptera: Culicidae) in China. Appl Entomol Zool. 2002;37:305-8.

38. Jaramillo-O N, Fonseca-González I, Chaverra-Rodríguez D. Geometric morphometrics of nine field isolates of Aedes aegypti with different resistance levels to lambda-cyhalothrin and relative fitness of one artificially selected for resistance. PLoS ONE. 2014;9:e96379.

39. Belinato TA, Valle D. The Impact of selection with diflubenzuron, a chitin synthesis inhibitor, on the fitness of two Brazilian Aedes aegypti field populations. PLoS ONE. 2015;10:e0130719.

40. Djogbénou L, Noel V, Agnew P. Costs of insensitive acetylcholinesterase insecticide resistance for the malaria vector Anopheles gambiae homozygous for the G119S mutation. Malar J. 2010;9:12.

41. Shute GT. A method of maintaining colonies of East African strains of Anopheles gambiae. Ann Trop Med Parasitol. 1956;50:92-4.

42. Alout H, Ndam NT, Sandeu MM, Djégbe I, Chandre F, Dabiré RK, et al. Insecticide resistance alleles affect vector competence of Anopheles gambiae s.s. for Plasmodium falciparum field isolates. PLoS ONE. 2013;8:e63849.

43. Yahouédo GA, Djogbénou L, Saïzonou J, Assogba BS, Makoutodé M, Gilles $J R L$, et al. Effect of three larval diets on larval development and male sexual performance of Anopheles gambiae s.s. Acta Trop. 2014;132:S96-101.

44. Kristan M, Lines J, Nuwa A, Ntege C, Meek SR, Abeku TA. Exposure to deltamethrin affects development of Plasmodium falciparum inside wild pyrethroid resistant Anopheles gambiae s.s. mosquitoes in Uganda. Parasit Vectors. 2016;9:100.

45. Mendes AM, Awono-Ambene PH, Nsango SE, Cohuet A, Fontenille $D$, Kafatos FC, et al. Infection intensity-dependent responses of Anopheles gambiae to the African malaria parasite Plasmodium falciparum. Infect Immun. 2011;79:4708-15.

46. Knöckel J, Molina-Cruz A, Fischer E, Muratova O, Haile A, Barillas-Mury C, et al. An impossible journey? The development of Plasmodium falciparum NF54 in Culex quinquefasciatus. PLoS ONE. 2013;8:e6338.

47. R Core Team. R: A language and environment for statistical computing (Version 323). Vienna: R Foundation Statistical Computing; 2015.

48. Shapiro SS, Wilk MB. An analysis of variance test for normality (complete samples). Biometrika. 1965;52:591-611.

49. Kaplan EL, Meier P. Nonparametric estimation from incomplete observations. J Am Stat Assoc. 1958;53:457-81.

50. Collett D. Modelling survival data in medical research. 2nd ed. London: Chapman and Hall/CRC; 2003. p. 408.

51. Ondeto BM, Nyundo C, Kamau L, Muriu SM, Mwangangi JM, Njagi K, et al. Current status of insecticide resistance among malaria vectors in Kenya. Parasit Vectors. 2017;10:429. 
52. Rowland M. Behaviour and fitness of $\mathrm{YHCH} /$ dieldrin resistant and susceptible female Anopheles gambiae and An stephensi mosquitoes in the absence of insecticide. Med Vet Entomol. 1991;5:193-206.

53. Sparks TC, Nauen R. IRAC: Mode of action classification and insecticide resistance management. Pest Biochem Physiol. 2015;121:122-8.

54. Kumar S, Thomas A, Samuel T, Sahgal A, Verma A, Pillai MKK. Diminished reproductive fitness associated with the deltamethrin resistance in an Indian strain of dengue vector mosquito Aedes aegypti L. Trop Biomed. 2009:26:155-64

55. Mebrahtu YB, Norem J, Taylor M. Inheritance of larval resistance to permethrin in Aedes aegypti and association with sex ratio distortion and life history variation. Am J Trop Med Hyg. 1997;56:456-65.

56. Okoye PN, Brooke BD, Hunt RH, Coetzee M. Relative developmental and reproductive fitness associated with pyrethroid resistance in the major southern African malaria vector Anopheles funestus. Bull Entomol Res. 2007:97:599-605.

57. Osoro JK, Machani MG, Ochomo E, Wanjala C, Omukunda E, Munga S, et al. Insecticide resistance exerts significant fitness costs in immature stages of Anopheles gambiae in western Kenya. Malar J. 2021;20:259.

58. Hauser G, Koella JC. Larval exposure to a pyrethroid insecticide and competition for food modulate the melanisation and antibacterial responses of adult Anopheles gambiae. Sci Rep. 2020;10:1364.

59. Nouage L, Elanga-Ndille E, Binyang A, Tchouakui M, Atsatse T, Ndo C, et al. Influence of GST- and P450-based metabolic resistance to pyrethroids on blood feeding in the major African malaria vector Anopheles funestus. PLOS ONE. 2020;15:e230984.

60. Kristan M, AbekuTA, Lines J. Effect of environmental variables and kdr resistance genotype on survival probability and infection rates in Anopheles gambiae (s.s.). Parasit Vectors. 2018;11:560.

\section{Publisher's Note}

Springer Nature remains neutral with regard to jurisdictional claims in published maps and institutional affiliations.

- fast, convenient online submission

- thorough peer review by experienced researchers in your field

- rapid publication on acceptance

- support for research data, including large and complex data types

- gold Open Access which fosters wider collaboration and increased citations

- maximum visibility for your research: over $100 \mathrm{M}$ website views per year

At BMC, research is always in progress.

Learn more biomedcentral.com/submissions 